\title{
ON GENERALIZED DAVIS-WIELANDT RADIUS INEQUALITIES OF SEMI-HILBERTIAN SPACE OPERATORS
}

\author{
Aniket Bhanja, Pintu Bhunia and Kallol Paul
}

Abstract. Let $A$ be a positive (semidefinite) operator on a complex Hilbert space $\mathscr{H}$ and let $\mathbb{A}=\left(\begin{array}{ll}A & O \\ O & A\end{array}\right)$. We obtain upper and lower bounds for the $A$-Davis-Wielandt radius of semiHilbertian space operators, which generalize and improve on the existing ones. Further, we derive upper bounds for the $A$-Davis-Wielandt radius of the sum of the product of semi-Hilbertian space operators. We also obtain upper bounds for the $\mathbb{A}$-Davis-Wielandt radius of $2 \times 2$ operator matrices. Finally, we determine the exact value for the $\mathbb{A}$-Davis-Wielandt radius of two operator matrices $\left(\begin{array}{cc}I & X \\ O & O\end{array}\right)$ and $\left(\begin{array}{cc}O & X \\ O & O\end{array}\right)$, where $X$ is a semi-Hilbertian space operator, and $I, O$ are the identity operator, the zero operator on $\mathscr{H}$, respectively.

Mathematics subject classification (2020): Primary 47A12, 46C05; Secondary 47A30, 47A50.

Keywords and phrases: A-Davis-Wielandt radius, $A$-numerical radius, $A$-operator seminorm, SemiHilbertian space.

\section{REFERENCES}

[1] M. L. ARias, G. Corach And M. C. GonZAlez, Lifting properties in operator ranges, Acta Sci. Math. (Szeged) 75: 3-4 (2009) 635-653.

[2] M. L. Arias, G. Corach AND M. C. GonZalez, Partial isometries in semi-Hilbertian spaces, Linear Algebra Appl. 428 (7) (2008) 1460-1475.

[3] M. L. Arias, G. Corach And M. C. Gonzalez, Metric properties of projections in semiHilbertian spaces, Integral Equations Operator Theory 62 (2008) 11-28.

[4] H. Baklouti, K. FeKi, O. A. M. Sid Ahmed, Joint normality of operators in semi-Hilbertian spaces, Linear Multilinear Algebra 68 (4) (2020) 845-866.

[5] H. BaKlouti, K. FeKi AND O. A. M. Sid Ahmed, Joint numerical ranges of operators in semiHilbertian spaces, Linear Algebra Appl. 555 (2018) 266-284.

[6] P. Bhunia, A. Bhanja, S. Bag And K. Paul, Bounds for the Davis-Wielandt radius of bounded linear operators, Ann. Funct. Anal. 12, 18 (2021), https://doi.org/10.1007/s43034-020-00102-9.

[7] P. BhUnia, R. K. NAYAK AND K. PAUl, Refinements of A-numerical radius inequalities and their applications, Adv. Oper. Theory 5 (2020) 1498-1511.

[8] P. Bhunia, K. FeKI And K. PAul, A-Numerical radius orthogonality and parallelism of semiHilbertian space operators and their applications, Bull. Iran. Math. Soc. 47 (2021), 435-457.

[9] P. BhUnia, K. PAUl AND R. K. NAYAK, On inequalities for A-numerical radius of operators, Electron. J. Linear Algebra 36 (2020) 143-157.

[10] P. Bhunia AND K. PAUl, Some improvement of numerical radius inequalities of operators and operator matrices, Linear Multilinear Algebra (2020), https://doi.org/10.1080/03081087.2020.1781037.

[11] L. DE Branges AND J. RovnyaK, Square summable power series, Holt, Rinehert and Winston, New York, 1966.

[12] C. DAVIS, The shell of a Hilbert-space operator, Acta Sci. Math., (Szeged) 29 (1968) 69-86. 
[13] R. G. Douglas, On majorization, factorization and range inclusion of operators in Hilbert space, Proc. Amer. Math. Soc. 17 (1966) 413-416.

[14] K. FEKI, Spectral radius of semi-Hilbertian space operators and its applications, Ann. Funct. Anal. 11 (2020) 929-946.

[15] K. FEKI, Generalized numerical radius inequalities of operators in Hilbert spaces, Adv. Oper. Theory 6, 6 (2021), https : //doi .org/10.1007/s43036-020-00099-x.

[16] K. FEKI, Inequalities for the A-joint numerical radius of two operators and their applications, arXiv:2005.04758v1 [math.FA] 10 May (2020).

[17] K. FEKI AND O. A. M. SID AhMED, Davis-Wielandt shells of semi-Hilbertian space operators and its applications, Banach J. Math. Anal. 14 (2020) 1281-1304.

[18] C.-K. Li AND Y.-T. Poon, Spectrum, numerical range and Davis-Wielandt Shell of a normal operator, Glasgow Math. J. 51 (2009) 91-100.

[19] C.-K. Li, Y.-T. Poon And N. S. SzE, Davis-Wielandt shells of operators, Oper. Matrices 2 (3) (2008) 341-355.

[20] B. Lins, I. M. Spitkovsky, S. Zhong, The normalized numerical range and the Davis-Wielandt shell, Linear Algebra Appl. 546 (2018) 187-209.

[21] W. Majdak, N. A. Secelean And L. Suciu, Ergodic properties of operators in some semiHilbertian spaces, Linear Multilinear Algebra 61 (2) (2013) 139-159.

[22] M. S. Moslehian, M. Kian, Q. XU, Positivity of $2 \times 2$ block matrices of operators, Banach J. Math. Anal. 13 (3) (2019) 726-743.

[23] A. SADDI, A-Normal operators in Semi-Hilbertian spaces, Aust. J. Math. Anal. Appl. 9 (1) Article 5 (2012) 1-12.

[24] H. Wielandt, On eigenvalues of sums of normal matrices, Pac. J. Math. 5 (1955) 633-638.

[25] A. Zamani, Some upper bounds for the A-numerical radius of $2 \times 2$ block matrices, Adv. Oper. Theory 6, 1 (2021), https : //doi .org/10.1007/s43036-020-00102-5.

[26] A. ZAMANI, A-numerical radius inequalities for semi-Hilbertian space operators, Linear Algebra Appl. 578 (2019) 159-183.

[27] A. Zamani And K. Shebrawi, Some Upper Bounds for the Davis-Wielandt Radius of Hilbert Space Operators, Mediterr. J. Math. 17, 25 (2020), https : //doi .org/10.1007/s00009-019-1458-z.

[28] A. Zamani, M. S. Moslehian, M.-T. Chien And H. NakaZato, Norm-parallelism and the Davis-Wielandt radius of Hilbert space operators, Linear Multilinear Algebra 67 (11) (2019) 21472158. 